\title{
DNA methylation as predictive marker of response to immunotherapy?
}

\author{
Gerwin Heller (D)
}

Received: 20 January 2021 / Accepted: 24 February 2021 / Published online: 31 March 2021

(C) The Author(s) 2021

\begin{abstract}
Summary Immunotherapy is one of the major breakthroughs in cancer treatment. However, many patients do not benefit from this type of therapy. Thus, there is an urgent need for a strategy to predict treatment efficacy before start of therapy. The role of certain genetic and epigenetic factors as potential predictive markers for response to immunotherapy is discussed in this short review.
\end{abstract}

Keywords Epigenetics - Biomarkers - Prediction · Oncology $\cdot$ Immune checkpoint inhibitors

$\begin{array}{ll}\text { Abbreviations } \\ \text { CGI } & \text { CpG island } \\ \text { CpG } & \text { Cytosine-guanine } \\ \text { CTLA4 } & \text { Cytotoxic T-lymphocyte-associated protein } 4 \\ \text { FFPE } & \text { Formalin-fixed paraffin-embedded } \\ \text { FOXP1 } & \text { Forkhead box P1 } \\ \text { ICI } & \text { Immune checkpoint inhibition } \\ \text { MMR } & \text { DNA mismatch repair } \\ \text { MSI } & \text { Microsatellite instability } \\ \text { NSCLC } & \text { Non-small cell lung cancer } \\ \text { ORR } & \text { Overall response rate } \\ \text { OS } & \text { Overall survival } \\ \text { PD1 } & \text { Programmed cell death protein 1 } \\ \text { PD-L1 } & \text { Programmed cell death 1 ligand 1 } \\ \text { PFS } & \text { Progression-free survival } \\ \text { SCLC } & \text { Small cell lung cancer } \\ \text { TMB } & \text { Tumor mutational burden }\end{array}$

G. Heller, PhD, MSc. (ه)

Division of Oncology, Department of Medicine I,

Medical University of Vienna, Waehringer Guertel

18-20, 1090 Vienna, Austria

gerwin.heller@meduniwien.ac.at

\section{Introduction}

Inhibition of immune checkpoint molecules-including cytotoxic T-lymphocyte-associated protein 4 (CTLA4), programmed cell death protein 1 (PD-1) and programmed cell death ligand 1 (PD-L1)-has become a promising treatment option for a number of advanced cancers over the past few years [1-6]. However, a significant proportion of patients will not benefit from this type of therapy. Thus, there is huge interest to identify molecular changes which may be used as markers to predict tumor response to immune checkpoint inhibitors (ICI).

Based on the mechanism of PD-1 and PD-L1 interaction, large effort has been taken to investigate the impact of PD-L1 expression on the efficacy of PD-1 inhibition [7]. Davis et al. retrospectively analyzed data from 45 clinical trials of anti-PD-1 or anti-PDL1 antibodies in 15 tumor entities and reported a predictive value of PD-L1 in $28.9 \%$ of these studies (not predictive in $53.3 \%$ and not tested in $17.8 \%$ ) [7]. Thus, although it seems that PD-L1 expression has some impact on the patients' outcome, it is imperfect as a reliable marker to predict tumor response to ICI, and additional markers or marker combinations are needed.

It is well known that human tumors may harbor a large number of somatic mutations with varying frequencies between tumor entities [8]. Nonsynonymous somatic mutations lead to altered amino acid sequences of proteins and formation of neoantigens. Thus, tumors with higher tumor mutational burden (TMB) carry a larger number of neoantigens which, in theory, increases their immunogenicity and their responsiveness to immunotherapy [9]. Indeed, associations between high TMB and response to ICI were reported in various cancer types including nonsmall cell lung cancer (NSCLC), small cell lung cancer 
(SCLC), melanoma and urothelial carcinoma [10-13]. However, other studies revealed no clear correlation between TMB and response to ICI [14, 15]. Thus, although the potential of TMB as predictive marker for response to ICI is high, additional studies focused on the definition of a predictive TMB cut-off, the establishment of a sequencing strategy to generate comparable TMB detection across different laboratories and combination of TMB and other potential markers are needed to further implement the use of TMB in routine practice.

Microsatellite instability (MSI) is a rare event in most solid tumor types (except colorectal and endometrial carcinomas) and may be caused by germline or somatic inactivation of genes involved in the DNA mismatch repair (MMR) pathway [16]. MSI represents a marker for predicting response to ICI, probably explained by increased expression of neoantigens caused by high genomic instability. In this context pembrolizumab is FDA approved for patients with MSI-H/deficient MMR metastatic or unresectable solid tumors, and nivolumab is approved for patients with MSI-H/deficient MMR metastatic colorectal cancer $[17,18]$. However, a variation in overall response rates (ORR) between tumor entities was observed. While patients with endometrial cancer had an ORR of $57.1 \%$, patients with pancreatic cancer and central nervous system (CNS) cancers had ORRs of $18.2 \%$ and $0 \%$, respectively, suggesting that MSI may serve as a tumor-type-specific predictive marker [18].

Besides genetic alterations epigenetic changes frequently occur in almost every type of cancer [19]. While the contribution of epigenetic aberrations to cancer development and progression was extensively studied over the past decade, knowledge about their role as predictive markers for ICI response is very limited and will be outlined here.

\section{What is epigenetics?}

Epigenetic mechanisms including DNA methylation and chemical modifications of histone proteins like methylation, phosphorylation, ubiquitination, acetylation and ADP-ribosylation significantly contribute to the regulation of transcriptional gene activity. These modifications are key events which affect transcription factor binding to DNA and change the chromatin structure resulting either in gene activation or gene silencing [20]. Epigenetic gene regulation is important for the regulation of many biological processes, including embryogenesis, genomic imprinting or X chromosome inactivation [19, 20].

DNA methylation is the covalent addition of a methyl group $\left(-\mathrm{CH}_{3}\right)$ to the $5^{\prime}$ carbon of cytosine bases within cytosine-guanine $(\mathrm{CpG})$ dinucleotides. In the mammalian genome the $\mathrm{CpG}$ dinucleotide is generally underrepresented [21]. However, certain regions of the genome $(0.5-4 \mathrm{~kb}$ in length) contain $\mathrm{CpG}$ dinucleotides at a high density and are called $\mathrm{CpG}$ islands (CGI). In humans, these regions are found in approximately $60 \%$ of gene promoter regions and less frequently in gene bodies or in intergenic regions [22]. While $70-80 \%$ of all non-CGI CpG dinucleotides in the human genome are methylated, cytosines of CpG dinucleotides in CGIs usually remain unmethylated. Exceptions are CGIs associated with imprinted, $\mathrm{X}$-linked and tissue-specific expressed genes [22].

DNA methylation is considered important in the pathogenesis of many solid tumors as well as hematological malignancies [19, 23]. CGIs of various cancer-related genes are frequently methylated in cancer cells, resulting in transcriptional inactivation of these genes [19, 24]. Of note, altered DNA methylation in regions outside $\mathrm{CpG}$ islands may be equally important in tumorigenesis, with hypomethylation as relevant as hypermethylation [25].

Several studies revealed that DNA methylation profiling may serve as novel tool in oncology for improved classification and differential diagnosis of carcinomas, especially brain tumors and sarcomas [26, 27]. Moreover, the potential of DNA methylation pattern as prognostic or predictive marker of response to specific therapies including chemotherapy, targeted therapy and immunotherapy in several tumor types was reported previously [28-30].

\section{DNA methylation as potential biomarker for immunotherapy}

DNA methylation in the human genome can be comprehensively profiled using high throughput assays based either on microarrays (e.g., Infinium HumanMethylation450 BeadChip, MethylationEPIC BeadChip; Illumina, San Diego, CA, USA) or next generation sequencing (e.g., reduced representaion bisulfite sequencing). MethylationEPIC beadChips are the latest generation of Illumina's beadarrays and are used to quantitatively analyze methylation of more than 850,000 methylation sites across the genome at singlenucleotide resolution. This approach is not restricted to fresh tissue samples but can also be applied to formalin-fixed paraffin-embedded (FFPE) tissue. In a multicenter study, Duruisseaux et al. [30] used this technology to analyze the methylome of stage IV NSCLC patients who were treated with anti-PD1-ICI during the course of their disease. In a first step, the authors analyzed tumors from 34 NSCLC patients before they received anti-PD1-ICI. Ten of these patients were classified as responders to this type of therapy and 24 patients were classified as nonresponders. Biostatistical analyses of the microarray data revealed a signature (referred to as EPIMMUNE signature) of 301 differentially methylated $\mathrm{CpG}$ sites (81\% hypermethylated; 19\% hypomethylated; associated with 174 unique genes) between responders and nonresponders. Pathway enrichment analyses revealed that some of these genes are involved in DNA repair, $\beta$-catenin signaling and interferon- $\gamma$ sig- 
naling. The EPIMMUNE signature was significantly associated with progression-free survival (PFS) and overall survival (OS) suggesting that EPIMMUNE may be a good predictor of anti-PD-1-ICI response [30]. Neither PD-L1 expression nor TMB were associated with PFS or OS in this patient cohort. In a second step, the authors performed similar experiments in an independent cohort of 47 patients with advanced NSCLC. Again, the EPIMMUNE signature was associated with PFS and OS supporting the predictive potential of this methylation signature [30]. Finally, to increase the usability of their findings in the future clinical routine, the authors identified the best single predictive methylation marker from the EPIMMUNE signature, namely forkhead box P1 (FOXP1). A third cohort of 61 NSCLC patients was tested for FOXP1 methylation using pyrosequencing and hypomethylation of this gene was found to be an independent predictor of PFS and OS in a multivariable model [30].

A similar approach to identify a set of CpG sites predictive for response to anti-PD-1/PD-L1 therapy in advanced NSCLC patients was published by Kim et al. [31]. In this study, tumor samples of 60 NSCLC patients were analyzed using MethylationEPIC beadChips and 377 differentially methylated CpG sites between responders and nonresponders were identified. The vast majority of these $\mathrm{CpG}$ sites were hypomethylated in nonresponders [31]. Based on these data, the authors calculated a predictive methylation model consisting of 8 genes (IRF6, CTSD, GRN, LTBR, TRIM36, EVL, CD3E and LCP1). Unfortunately, the authors did not provide information about the predictive value of FOXP1 methylation in their patient cohort. Noteworthy, the clinical benefit in this cohort was not associated with $\mathrm{TMB}$, neo-antigen load, aneuploidy level or PD-L1 expression [31].

An example of a single DNA methylation event as potential predictive marker for immunotherapies was reported by Goltz et al. in melanoma patients [32]. The authors analyzed methylation of the CTLA4 promoter in a set of 50 anti-PD-1/CTLA-4-ICI treated patients with metastasized malignant melanoma by methylation-specific quantitative real-time PCR. Low CTLA4 methylation was significantly correlated with response to therapy and OS [32].

In summary, the above mentioned studies suggest that DNA methylation pattern may be of predictive relevance for response to immunotherapies in the future; however, available data are still very limited and a multitude of additional studies are needed to strengthen this concept.

\section{Take home message}

Treatment with $\mathrm{ICl}$ can generate durable responses in a subset of cancer patients. Promising data about TMB, $\mathrm{MSI}$ and DNA methylation as future markers to predict response to $\mathrm{ICl}$ are available.
Funding Open access funding provided by Medical University of Vienna.

Conflict of interest G. Heller received research funding from Bristol Myers Squibb and Merck MSD.

Open Access This article is licensed under a Creative Commons Attribution 4.0 International License, which permits use, sharing, adaptation, distribution and reproduction in any medium or format, as long as you give appropriate credit to the original author(s) and the source, provide a link to the Creative Commons licence, and indicate if changes were made. The images or other third party material in this article are included in the article's Creative Commons licence, unless indicated otherwise in a credit line to the material. If material is not included in the article's Creative Commons licence and your intended use is not permitted by statutory regulation or exceeds the permitted use, you will need to obtain permission directly from the copyright holder. To view a copy of this licence, visit http://creativecommons.org/licenses/by/4.0/.

\section{References}

1. BrahmerJ, Reckamp KL, Baas P, Crino L, EberhardtWE, Poddubskaya E, et al. Nivolumab versus Docetaxel in advanced squamous-cell non-small-cell lung cancer. N Engl J Med. 2015;373(2):123-35.

2. Motzer RJ, Tannir NM, McDermott DF, Aren Frontera O, Melichar B, Choueiri TK, et al. Nivolumab plus ipilimumab versus sunitinib in advanced renal-cell carcinoma. N Engl J Med. 2018;378(14):1277-90.

3. Gandhi L, Rodriguez-Abreu D, GadgeelS, Esteban E, FelipE, De Angelis F, et al. Pembrolizumab plus chemotherapy in metastatic non-small-cell lung cancer. N Engl J Med. 2018;378(22):2078-92.

4. Paz-Ares L, Luft A, Vicente D, Tafreshi A, Gumus M, Mazieres J, et al. Pembrolizumab plus chemotherapy for squamous non-small-cell lung cancer. N Engl J Med. 2018;379(21):2040-51.

5. Ascierto PA, Del Vecchio M, Mandala M, Gogas H, Arance AM, Dalle S, et al. Adjuvant nivolumab versus ipilimumab in resected stage IIIB-C and stage IV melanoma (CheckMate 238): 4-year results from a multicentre, double-blind, randomised, controlled, phase 3 trial. Lancet Oncol. 2020;21(11):1465-77.

6. Bellmunt J, de Wit R, Vaughn DJ, Fradet Y, Lee JL, Fong L, et al. Pembrolizumab as second-line therapy for advanced urothelial carcinoma. NEngl J Med. 2017;376(11):1015-26.

7. Davis AA, Patel VG. The role of PD-L1 expression as a predictive biomarker: an analysis of all US Food and Drug Administration (FDA) approvals of immune checkpoint inhibitors. J Immunother Cancer. 2019;7(1):278.

8. Martincorena I, Campbell PJ. Somatic mutation in cancer and normal cells. Science. 2015;349(6255):1483-9.

9. Choucair K, Morand S, Stanbery L, Edelman G, Dworkin L, Nemunaitis J. TMB: a promising immune-response biomarker, and potential spearhead in advancing targeted therapy trials. Cancer Gene Ther. 2020;27(12):841-53.

10. Rosenberg JE, Hoffman-Censits J, Powles T, van der Heijden MS, Balar AV, Necchi A, et al. Atezolizumab in patients with locally advanced and metastatic urothelial carcinoma who have progressed following treatment with platinumbased chemotherapy: a single-arm, multicentre, phase 2 trial. Lancet. 2016;387(10031):1909-20.

11. Hellmann MD, Ciuleanu TE, Pluzanski A, Lee JS, Otterson GA, Audigier-Valette C, et al. Nivolumab plus Ip- 
ilimumab in lung cancer with a high tumor mutational burden. N Engl J Med. 2018;378(22):2093-104.

12. Hellmann MD, Callahan MK, Awad MM, Calvo E, Ascierto PA, Atmaca A, et al. Tumor mutational burden and efficacy of nivolumab monotherapy and in combination with Ipilimumab in small-cell lung cancer. Cancer Cell. 2019;35(2):329.

13. Goodman AM, Kato S, Bazhenova L, PatelSP, Frampton GM, Miller V, et al. Tumor mutational burden as an independent predictor of response to immunotherapy in diverse cancers. MolCancer Ther. 2017;16(11):2598-608.

14. Miao D, Margolis CA, Gao W, Voss MH, LiW, Martini DJ, et al. Genomic correlates of response to immune checkpoint therapies in clear cell renal cell carcinoma. Science. 2018;359(6377):801-6.

15. Klempner SJ, Fabrizio D, Bane S, Reinhart M, Peoples T, Ali SM, et al. Tumor mutational burden as a predictive biomarker for response to immune checkpoint inhibitors: a review of current evidence. Oncologist. 2020;25(1):e147-e59.

16. Trabucco SE, Gowen K, Maund SL, Sanford E, Fabrizio DA, Hall MJ, etal. Anovel next-generation sequencing approach to detecting microsatellite instability and pan-tumor characterization of 1000 microsatellite instability-high cases in 67,000 patient samples. J Mol Diagn. 2019;21(6):1053-66.

17. Le DT, Kim TW, Van Cutsem E, Geva R, Jager D, Hara H, et al. Phase II open-label study of pembrolizumab in treatment-refractory, microsatellite instability-high/mismatch repair-deficient metastatic colorectal cancer: KEYNOTE164. JClin Oncol. 2020;38(1):11-9.

18. Marabelle A, Le DT, Ascierto PA, Di Giacomo AM, De JesusAcosta A, Delord JP, et al. Efficacy of pembrolizumab in patients with noncolorectal high microsatellite instability/ mismatch repair-deficient cancer: results from the phase II KEYNOTE-158 study. JClin Oncol. 2020;38(1):1-10.

19. Sandoval J, Esteller M. Cancer epigenomics: beyond genomics. Curr Opin Genet Dev. 2012;22(1):50-5.

20. Zhang L, Lu Q, Chang C. Epigenetics in health and disease. AdvExp Med Biol. 2020;1253:3-55.

21. Deaton AM, Bird A. CpG islands and the regulation of transcription. Genes Dev. 2011;25(10):1010-22.

22. Jones PA. Functions of DNA methylation: islands, start sites, gene bodies and beyond. Nat Rev Genet. 2012;13(7):484-92.

23. Heller G, Topakian T, Altenberger C, Cerny-Reiterer S, Herndlhofer S, Ziegler B, et al. Next-generation sequencing identifies major DNA methylation changes during progression of $\mathrm{Ph}+$ chronic myeloid leukemia. Leukemia. 2016;30(9):1861-8.

24. Heller G, Babinsky VN, Ziegler B, Weinzierl M, Noll C, Altenberger $\mathrm{C}$, et al. Genome-wide $\mathrm{CpG}$ island methylation analyses in non-small cell lung cancer patients. Carcinogenesis. 2013;34(3):513-21.

25. Irizarry RA, Ladd-Acosta C, Wen B, Wu Z, Montano C, Onyango $\mathrm{P}$, et al. The human colon cancer methylome shows similar hypo- and hypermethylation at conserved tissue-specific CpG island shores. Nat Genet. 2009;41(2):178-86.

26. Capper D, Jones DTW, Sill M, Hovestadt V, Schrimpf D, Sturm D, et al. DNA methylation-based classification of central nervous system tumours. Nature. 2018;555(7697):469-74.

27. Koelsche C, Kriegsmann M, Kommoss FKF, Stichel D, Kriegsmann K, Vokuhl C, et al. DNA methylation profiling distinguishes Ewing-like sarcoma with EWSR1-NFATc2 fusion from Ewing sarcoma. J Cancer Res Clin Oncol. 2019;145(5):1273-81.

28. Cancer Genome Atlas Research Network, Electronic address edsc, Cancer Genome Atlas Research N. Comprehensive and Integrated Genomic Characterization of Adult Soft Tissue Sarcomas. Cell. 2017;171(4):950-965e28. e28.

29. Sigin VO, Kalinkin AI, Kuznetsova EB, Simonova OA, Chesnokova GG, Litviakov NV, et al. DNA methylation markers panel can improve prediction of response to neoadjuvant chemotherapy in luminal B breast cancer. Sci Rep. 2020;10(1):9239.

30. Duruisseaux M, Martinez-Cardus A, Calleja-Cervantes ME, MoranS, Castro deMoura M, Davalos V, etal. Epigenetic prediction of response to anti-PD-1 treatment in non-smallcell lung cancer: a multicentre, retrospective analysis. Lancet Respir Med. 2018;6(10):771-81.

31. KimJY, Choi JK, JungH.Genome-widemethylation patterns predict clinical benefit of immunotherapy in lung cancer. Clin Epigenetics. 2020;12(1):119.

32. Goltz D, Gevensleben H, Vogt TJ, Dietrich J, Golletz C, Bootz F, et al. CTLA4 methylation predicts response to anti-PD-1 and anti-CTLA-4 immunotherapy in melanoma patients. JCI Insight. 2018;3(13). https://doi.org/10.1172/jci.insight. 96793

Publisher's Note Springer Nature remains neutral with regard to jurisdictional claims in published maps and institutional affiliations.

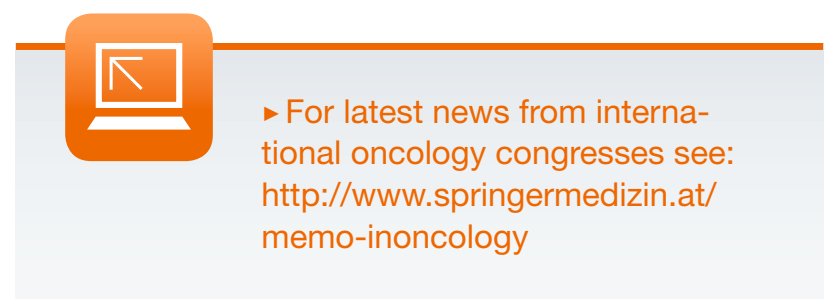

